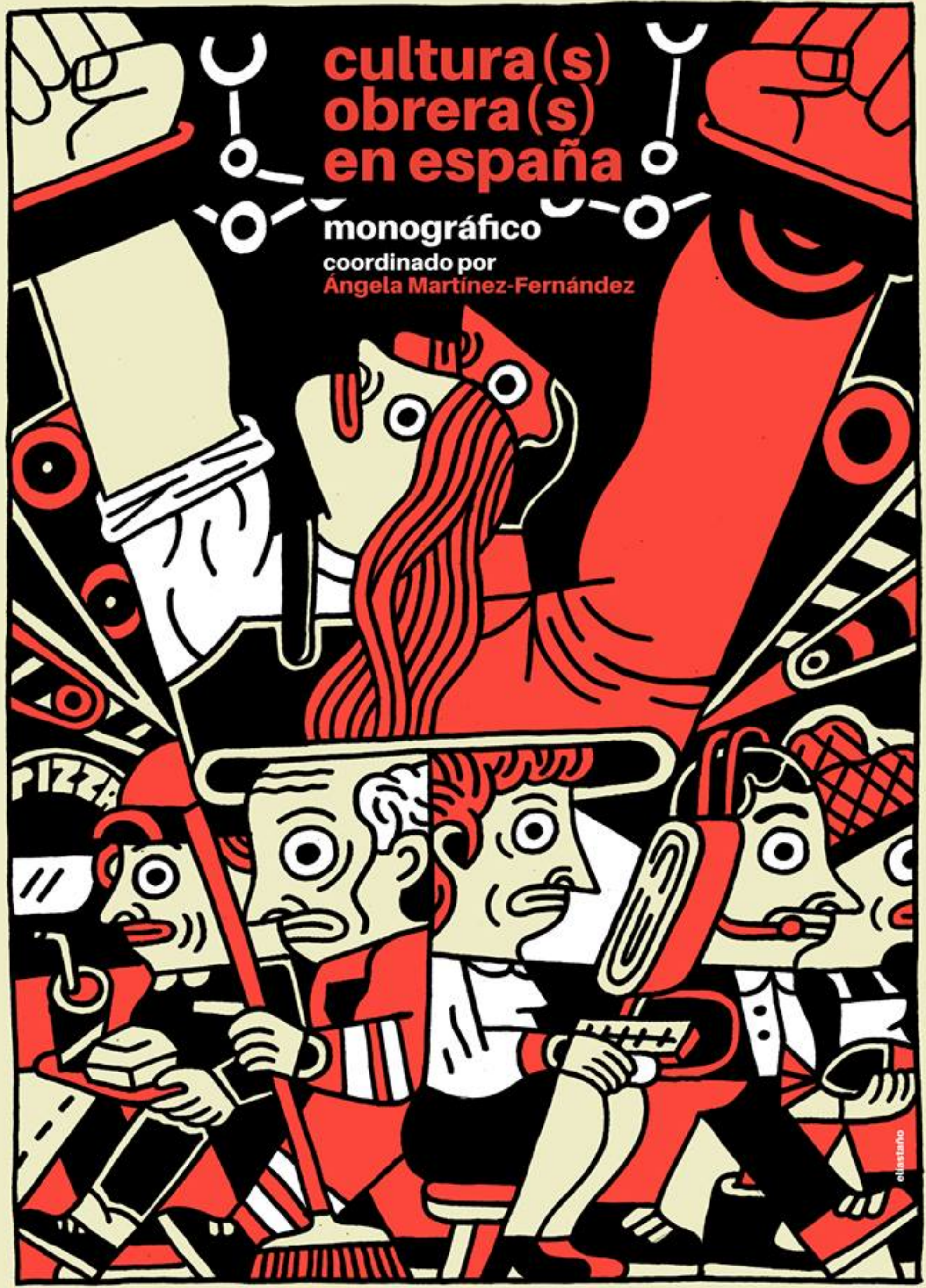




\title{
CUltura(S) OBRERA(S) EN ESPAÑA
}

\author{
KAMCHATKA. REVISTA DE ANÁLISIS CULTURAL 14 (2019) \\ Monográfico coordinado por ÁNGELA MARTíNEZ FERNÁNDEZ \\ Diseño de portada: ELÍAS TAÑO
}

ÁNGELA MARTÍNEZ FERNÁNDEZ. Cultura(s) obrera(s) en España.

\section{LA HISTORICIDAD DE LAS CULTURAS OBRERAS}

RAQUEL ARIAS CAREAGA. Riesgos y manipulaciones en la recuperación de la obra de Andrés Carranque de Ríos.

GUillermo PASTOR NúÑEZ. Un archivo vivo de la guerra civil española. El auténtico archivo de la guerra.

Alejandro Civantos UrRutia. La Enciclopedia del Obrero. La revolución 111-135 editorial anarquista 1881-1923.

Antonio Plaza Plaza. El teatro proletario en Madrid. Del grupo Nosotros a la compañía de teatro proletario de César Falcón (1931-1934)

Lucía Hellín Nistal. 'Tea Rooms. Mujeres obreras': una novela de avanzada de Luisa Carnés.

Rocío Negrete PeÑA. María Arondo, ¿una voz representativa de las 'bonnes' españolas en París? Clase, género, raza y migración.

CRISTINA SOMOLINOS. "Las mujeres hacemos fuerza, aunque los hombres quieran negarlo": el trabajo doméstico bajo el franquismo en la narrativa social de Dolores Medio.

SORAYA GAHETE MuÑoz. ¿Sexo contra sexo o clase contra clase? El género y la clase en los debates del feminismo español (1975-1980).

\section{UNA IMAGEN VALE MÁS QUE MIL PALABRAS. CULTURA VISUAL OBRERA}

MAURA Rossi. Obreros de la imagen: memoria(s) de Gerda Taro.

MARTA PiÑOL LlORET. Las culturas de la emigración española: reflejos 289-316 audiovisuales de la clase obrera. 
III. PROPUESTAS PARA Y SOBRE EL PRESENTE

DAVID BECERra Mayor. Leer desde la ruptura. Propuesta teórica para explorar el 319-348 potencial político de una genealogía literaria interrumpida.

CÉSAR DE VICENTE HERNANDO. Cultura obrera: un intento de definición.

Carolina F. Cordero. Blocos/batucadas en los barrios obreros de Madrid. La 367-387 percusión colectiva como cultura de clase.

CRISTINA SOMOLINOS. Cartografías de la precariedad laboral: la escritura colectiva 389-412 de 'Precarias a la deriva'.

\section{POSIBILIDADES DE INTERNACIONALISMO}

DARÍO DAWYD. Representaciones del sindicalismo peronista en la obra del sociólogo argentino Roberto Carri. Tres momentos, del vandorismo a Montoneros (1967-1974).

MARTina MoriCONi. Los trabajadores de la fábrica Jabón Federal de La Matanza en los años setenta: una reconstrucción histórica y diferentes narrativas.

MARIANA SOL CANDA Un corresponsal en cada fábrica'. La búsqueda de la CGTA 469-487 para dar voz a las bases en su Semanario.

\section{MATERIALES PARA LA DiSCUSIÓN DE LAS CULTURAS OBRERAS}

Un gesto de escucha. De Rigoberta Menchú a Las que limpian los hoteles: aplicaciones y límites de la subalternidad en el cambio de siglo. Conversación con MERCÈ PICORNELL.

De la (des)memoria a la sociedad del espectáculo. Descubrimiento, trayectoria y repercusión de la figura de Luisa Carnés. Entrevista a ILIANA OLMEDO.

[A tiro de] [Barrio]. Entrevista al colectivo teatral ATIROHECHO 561-575

ELÍAs TAÑo. Nos creíamos libres. $\quad$ 577-585 


\title{
OBREROS DE LA IMAGEN: MEMORIA(S) DE GERDA TARO
}

Workers of the image: memory(ies) of Gerda Taro

\author{
MAURA ROSSI \\ UNIVERSITÀ DEGLI STUdi DI PADOVA (ITALIA) \\ maura.rossi@unipd.it http://orcid.org/0000-0003-0343-814X
}

RECIBIDO: 31 DE ENERO DE 2019 ACEPTADO: 4 DE JUNIO DE 2019

RESUMEN: Entre los nombres ilustres del fotoperiodismo internacional que acudieron a España durante la guerra civil, el de Gerda Taro se ha vuelto a destapar recientemente tras varias décadas de olvido. Pieza fundamental del trabajo cooperativo que supuso la elaboración de una iconografía de la República española y de la lucha tanto de las asociaciones de trabajadores como, más en general, del pueblo acosado por el fascismo, el trabajo de Taro es una faceta todavía escasamente conocida del esfuerzo mediático, ideológico y político por la constitución de un movimiento internacionalista que opusiera una resistencia compacta a la avanzada del totalitarismo nacionalista en Europa. Descomponiendo tanto la autonarración construida por la misma Taro como la mitificación de su muerte en el frente de Brunete llevada a cabo por el Partido Comunista Francés o las más recientes ficciones narrativas donde aparece como personaje literario, finalidad de este trabajo es reconstruir cuáles son las diferentes etapas y las bases argumentativas del largo proceso de transmisión del recuerdo compartido de la joven fotógrafa, con el objetivo final de establecer si ha llegado a la contemporaneidad un reconocimiento adecuado para su aportación a la lucha antifascista.

PALABRAS CLAVE: Gerda Taro, Guerra Civil española, internacionalismo, fotografía de guerra, postmemoria.

ABSTRACT: Among the famous names of international photojournalism who converged in Spain during the Civil War, Gerda Taro's was only recently rediscovered after many decades of oblivion. A fundamental piece of the cooperative action which aimed to the elaboration of an iconography of the Spanish Republic and of the fight undertaken both by the trade unions and, more generally, by the Spanish people menaced by fascism, Taro's work is a still partially unknown page of the mediarelated, ideological and political effort towards the constitution of an internationalist movement which was to oppose compactly the raise of nationalist totalitarianism in Europe. Through an analysis of the auto-narration sketched by Taro herself, as well as of the mitification of her death iconized by the French Communist Party and some more recent fictional works where she appears as a literary character, the main aim of this article is to reconstruct the different stages in the construction and transmission of Taro's collective memory. The ultimate objective is to evaluate where a proper recognition for her antifascist effort has reached the contemporaneity.

KEYwords: Gerda Taro, Spanish Civil War, Internationalism, War Photography, Postmemory. 


\section{INTRODUCCIÓN}

El artículo trata de desarrollar una exploración diacrónica de la figura histórica de Gerda Taro, pieza fundamental en el proceso de configuración del fotoperiodismo contemporáneo que quedó notablemente impulsado -acaso incluso fundado- durante la Guerra Civil española, espacio de experimentación solidaria de los que podrían definirse como obreros de la imagen con la acción de los movimientos de trabajadores activos en defensa de la República.

A través de un análisis pormenorizado antes de su acercamiento a la lucha proletaria internacionalista y después de su contribución activa - esto es, sobre todo iconográfica y propagandística- al antifascismo europeo, la argumentación propuesta tratará de comprender las bases de la construcción y efímera fijación del mito político de Taro a raíz de su muerte en el frente, con el objetivo final de descomponer las distintas etapas de su exaltación, sucesivo olvido y reciente redescubrimiento (incluso literario), aportando una perspectiva interdisciplinaria y actualizada a los numerosos estudios acerca de su breve trayectoria profesional. La finalidad última es la evaluación del legado (post)mnemónico que queda de Taro en la contemporaneidad, con una atención específica por la evaluación de su eficacia a la hora de devolver a la memoria colectiva española y europea el perfil de una joven antifascista pionera en su conciencia del poder de la imagen para informar al gran público y sacudir transversalmente las conciencias.

\section{FOTOPERIODISMO Y LUCHA POLÍTICA: LOS PRIMEROS PASOS DE GERDA TARO}

A la hora de acercarse a la cultura obrera europea de los años treinta del siglo XX desde un punto de vista iconográfico y, más específicamente, fotográfico, el nombre de Robert Capa acaso sobresalga entre los más relevantes en lo que se refiere a la producción y a la circulación de instantáneas que supieron inmortalizar la resistencia ideológica y material de ciertas masas de trabajadores ante la difusión rápida e infecciosa del fascismo. Activo antes en París y, más tarde, en la España de la guerra civil, el glamuroso personaje que el fotógrafo supo construir a partir de su menos peculiar identidad de exiliado húngaro de familia judía sigue siendo considerado en la contemporaneidad como un pionero de la cámara en la configuración del fotoperiodismo tal y como todavía se concibe; esto es, un acercamiento extremo y en ocasiones no exento de peligros a un sujeto significativo, la producción consiguiente de una imagen impactante y transversalmente empatizante y, para acabar, la circulación rápida del producto final con un alcance lo más amplio posible1. Si la muerte casi cinematográfica de Capa en el frente de la guerra de Indochina no hizo sino eternizar el recorrido de uno de los testigos más elocuentes de la historia del siglo XX, se registra un destino casi opuesto para el recuerdo colectivo de Gerda Taro, que fue su aprendiz y compañera de vida tanto en la capital francesa como en la guerra de España y quien asimiló los primeros rudimentos de fotografía en el París de la primera mitad de los treinta, bebiendo de los debates originados por las vanguardias en relación con el compromiso de las artes con los movimientos obreros y, al mismo tiempo, averiguando cómo el asociacionismo de los trabajadores franceses movía los primeros pasos hacia la constitución de un Frente Popular y,

\footnotetext{
${ }^{1}$ El refrán de la justa distancia del sujeto - ni demasiado cerca, ni demasiado lejos- ha sido fijada por Cornell Capa en Slightly out of focus, edición foto-ilustrada de las memorias de su hermano en la Segunda Guerra Mundial (Capa, 2001).
} 
símilmente a lo que acontecería en España, empezaba a invocar la acción internacional de la clase trabajadora ante el fortalecimiento consistente de los nacionalismos ${ }^{2}$.

Nacida en Stuttgart en la familia Pohorylle, de judíos de procedencia polaca, la historia de Taro resulta bastante oscurecida por las múltiples narraciones de las que ha sido el objeto, tanto durante la vida de la fotógrafa, que tras su exilio en París vertebró para ella y para Capa unos alias funcionales a la venta de sus negativos, como y sobre todo después de su muerte, cuando fue convertida por el Partido Comunista Francés - con el apoyo de las representaciones en París de la República Española- en una suerte de mártir proletaria, para luego sufrir, a raíz de los avatares de la Segunda Guerra Mundial, una obliteración casi completa de la memoria colectiva tanto francoespañola como proletaria ${ }^{3}$. Para tratar de entender cómo una joven fotógrafa extranjera se convirtió antes en un icono político del antifascismo internacional en España, y al mismo tiempo para evaluar qué es lo que queda hoy en día de semejante versión de su breve trayectoria en la península ibérica, es ante todo imprescindible distinguir entre un entonces -que empieza con su propia performance 4 y acaba con el homenaje post-mortem, ambos basados en las elecciones o en el recorrido vital de Taro- y un ahora que se corresponde con las elaboraciones más recientes alrededor de su figura, por lo general aparecidas en las primeras décadas del siglo XXI, tras más de sesenta años de olvido.

Las primeras elaboraciones sobre Gerda Taro, antes personales y en un segundo momento culturales, responden de alguna manera a las solicitaciones impulsadas por el empleo reciente de la fotografía como medio de información y, no secundariamente, de propaganda, en una época liminal para la historia de Europa, en la cual el consenso de los colectivos sociales iba adquiriendo con toda evidencia un carácter decisivo. Los trabajos que se enfrentan con la herencia política de la fotógrafa en una época más reciente coinciden, en cambio, por un lado, con una serie de iniciativas culturales vinculadas con la fotografía (en las cuales el factor ideológico resulta a menudo supeditado al valor histórico de la imagen); por el otro, con recreaciones narrativas que pertenecen al marco de la ficción y convierten a Taro en un personaje de la literatura de la memoria post-traumática, cuyo éxito a partir de finales de los noventa no parece todavía agotado en España.

En lo referente a la auto-creación de Taro, puede decirse que semejante operación corresponde a un camuflaje prudente de su procedencia tanto geográfica como cultural, llevado a cabo como medida de adaptación a un medio ambiente parisino que, en el torbellino de las tensiones sociales provocadas por el impacto todavía punzante del primer conflicto mundial en la

\footnotetext{
2 Para una profundización de la cuestión obrera en relación con la constitución del Front Populaire francés remito al análisis puntual desarrollado en Wolikow (1996). Una panorámica sugerente de la contribución de los fotógrafos activos en el París de los treinta a la difusión de reportajes relativos a las iniciativas de los trabajadores puede, en cambio, encontrarse en Cartier-Bresson et al. (2006).

3 Al hablar de memoria colectiva como categoría sociológica hago referencia a la conocida teoría de Maurice Halbwachs, quien analiza los recuerdos compartidos de hechos históricos como señas de identidad que resultan perpetuadas al ser consideradas relevantes por un determinado grupo social, político o familiar (véanse Halbwachs, 1950 y Halbwachs, 1994).

${ }^{4}$ Adaptando el análisis propuesto en Butler (1988), la invención de Gerda Taro por parte de Gerta Pohorylle puede definirse performativa en cuanto se funda en una "identidad" funcional al nuevo ambiente social, "constituida a lo largo de cierto tiempo" y basada en una "estilización" del sujeto que la crea (Butler, 1988: 519, la traducción es mía).
} 
economía del país, empezaba a mal soportar la llegada masiva de refugiados alemanes y, como subrayan Jenkins y Millington (2015), no se libraba de la aparición en sus calles de grupos xenófobos y antisemitas que imitaban el modelo de las escuadras hitlerianas y fascistas. Bien mirado, como reconstruye Irme Schaber (2007) en su biografía de Taro, la joven se había alejado de Leipzig, donde su familia se había mudado en 1929, justamente debido al creciente control del partido y de los grupos Nazis de acción en la vida diaria de los ciudadanos: ella misma había sufrido limitaciones por ser judía y había sido detenida durante dos semanas en el marco de una redada en contra de los opositores políticos 5 . En París, por lo tanto, no era aconsejable ser identificable como alemana, prófuga y judía, elementos a los que se acompañaba el hecho de ser una mujer soltera alejada de la familia de origen, en un contexto europeo en que la emancipación femenina, pese a formar parte del discurso político de los movimientos obreros, resultaba todavía embrionaria en el marco urbano pequeño-burgués.

Taro, entonces, empezó a construir su independencia económica por medio de una serie de oficios provisionales entre los que la fotografía inicialmente no era sino uno más ${ }^{6}$; minimizó una identidad judía a la que, criada en un ambiente familiar escasamente interesado en la religión, no tenía ningún apego íntimo; defendió su derecho a la autodeterminación sentimental interrumpiendo la relación que había empezado en Leipzig con un miembro de las Juventudes Comunistas entonces exiliado a Italia y eligiendo sus frecuentaciones amorosas sin fijarse demasiado en la conveniencia - lo cual en la ficción actual ha sido frecuentemente mistificado bajo el filtro estereotipado de la femme fatale-; y, por último, se alejó definitivamente del aura burguesa en la que la sumergían sus orígenes familiares -los informantes de Schaber convergen en confirmar que no había secretos dentro del microcosmos de los exiliados- sumándose al milien intelectual y político que puede etiquetarse como inclusivamente revolucionario y crecientemente consciente de la necesidad de construir una resistencia compacta, internacional y universal ante la acción arrolladora de los partidos nacionalistas.

Una vez más, si la identificación política de Taro no se tradujo en ninguna afiliación oficial -no es posible establecer si debido a una voluntad de discreción o a una indeterminación efectiva de su identificación política-, sí consta su presencia, primero personal y en un segundo momento

\footnotetext{
5 Aunque en los archivos de las asociaciones políticas juveniles de Leipzig no conste ninguna ficha a nombre de Gerda, reconstruyendo las frecuentaciones de la joven, Schaber defiende su cercanía a diferentes agrupaciones de trabajadores y su participación -no es posible conocer con qué nivel de implicación- en las actividades pacíficas de oposición al nacionalsocialismo. En particular, los testigos consultados por la biógrafa recuerdan la presencia de Taro en mítines y demonstraciones promovidos antes por "la Liga de los Estudiantes Socialistas, la Unión de Juventudes Comunistas, o KJVD, y [...] los Jóvenes Pioneros" y, después de su constitución en 1932, por el "Partido Socialista Obrero, SAP”, el primero en abogar por la constitución de un frente popular alemán de oposición a Adolf Hitler (Schaber, 2007: 52 y 59, la traducción es mía). Aunque en su biografía novelada, Fernando Olmeda (2007: 50) no dude en definir a la fotógrafa como "una joven seductora y militante" -apoyándose en una declinación romántica que banaliza profundamente el dato político-, más que un activismo banderizo declarado resulta prudente suponer, por lo menos a estas alturas, cierta cercanía de Taro con una conciencia de clase que se oponía fácticamente al recién adquirido estatus burgués de su familia de comerciantes y que a la vez había plenamente cundido en las elecciones políticas de sus hermanos mayores, miembros del "RGO, el sindicato de oposición revolucionaria comunista" y objetivos primarios de la incursión en la casa de los Pohorylle la noche de la detención de Gerda (Schaber, 2007: 65).

6 Según subraya Schaber (2007) -y según recogen la mayoría de las narraciones contemporáneas acerca de la fotógrafa- Taro empezó a acercarse a la cámara ocasionalmente como modelo, y pasó al otro lado del objetivo gracias a su encuentro con Robert Capa en 1934.
} 
profesional, en círculos, asociaciones, manifestaciones y mítines tanto de la juventud alemana en el exilio como del ambiente obrero parisino ${ }^{7}$. En particular, a partir de 1935, cuando ya estaba familiarizándose con el oficio de la imagen asistiendo a Capa tanto en la faceta práctica de su trabajo como en la colocación y venta de sus instantáneas a diferentes periódicos franceses e internacionales, se hizo "miembro [de la] AEAR, la Asociación de los Escritores y Artistas Revolucionarios" concebida como "la sección francesa de la Asociación Internacional de los Escritores" (Schaber, 2007:102) ${ }^{8}$. Aplicando una mirada retroactiva al trabajo que Taro llevó a cabo en España poco más de un año después, surge espontáneo divisar en la perspectiva ideológica que subyace a la concepción de sus instantáneas el eco de las discusiones organizadas en el seno de la Asociación en relación con la necesidad de que el arte se comprometiera con la información, concienciación y educación capilares de las masas y que a la vez prestara su pluma, pincel u objetivo a la configuración colaborativa de una narración del proletariado que desencadenara a la vez una identificación hasta la fecha inalcanzada -e inalcanzable - por el arte burgués y una llamada a un sentido transversal e internacional de la comunidad, sobre todo obrera. En el marco de semejantes reflexiones trans-semióticas, que apoyándose en el análisis de Louis Aragon (1935) pueden referirse al más amplio debate sobre el realismo socialista9 ${ }^{9}$ la iconografía mantenía, como es de esperar, un lugar prominente, debido a su alto poder de condensación de la información -o del mensaje- dentro del espacio limitado de un rectángulo de papel que corre fácilmente de mano en mano, y a su universalidad, esto es, su impacto accesible, que no precisaba de la alfabetización para ser decodificado. A modo de hipónimo, gracias a su versatilidad para la reproducción en serie y a su aparente (aunque ilusoria) cercanía íntima con la realidad, la fotografía comenzaba:

a ser pieza $[\ldots]$ probatoria $[\ldots]$ en el proceso histórico. En ello consiste su oculta significación política. [Las instantáneas] exigen por primera vez que su recepción se haga con un sentido determinado. La contemplación carente de compromiso no es ya la adecuada para ellas. Inquietan al observador, que siente que debe encontrar una determinada vía de acceso a ellas. Los periódicos ilustrados comienzan a ofrecerle esa vía. Correctas o erradas da igual. En ellos, los pies de foto se vuelven por primera vez

\footnotetext{
${ }^{7}$ Símilmente respecto a la reconstrucción de sus simpatías políticas en Leipzig, Schaber apoya las suposiciones sobre la trayectoria parisina de Taro en los testimonios de amigos y conocidos que recuerdan la presencia de la joven en los ambientes de la lucha proletaria o de los debates intelectuales relacionados con la implicación del arte en la contingencia. Se trata de una memoria transmitida que ha sido completamente absorbida, y en algunos casos magnificada, en la construcción post-mortem del recuerdo público de la fotógrafa.

8 Reconstruye Nicole Racine (1966: 29) que “L’A.E.A.R., fondée en mars 1932 par des écrivains communistes et sympathisants, se donnait pour but -conformément aux directives soviétiques- la constitution d'un front d'intellectuels, unis sur les mots d'ordre de lutte idéologique contre la guerre et le fascisme, dans les perspectives qui étaient celles de L'Internationale communiste. La constitution de l'A.E.A.R. coïncide avec un tournant dans la vie intellectuelle soviétique qui se traduit par l'abandon de positions étroitement 'prolétariennes' et l'appel aux 'compagnons de lutte"'.

9 Para una profundización relativa a la llamada "querelle du réalisme" en los debates organizados por la A.E.A.R. remito a Racine (2003), mientras que una perspectiva general sobre el rol de la fotografía en el París de las luchas obreras puede encontrarse en Denoyelle (1997).
} 
indispensables. $\mathrm{Y}$ es claro que su carácter es completamente diferente del que tiene el título de una pintura ${ }^{10}$. (Benjamin, 2003: 58-59)

A este contexto donde la fotografía quiebra las barreras elitistas del intelectualismo exclusivo para aportar su contribución a la lucha política cabe adscribir el que acaso pueda considerarse como el clímax de la operación de renovación llevada a cabo por Taro con respecto a su identidad, esto es, la obtención de una acreditación profesional por medio de la cual la agencia fotográfica A.B.C. Press-Service, basada en Ámsterdam y ya comitente del trabajo de Capa, la contrató como journaliste ${ }^{11}$. Ese documento, además de garantizarle un vital permiso de permanencia legal dentro del territorio francés, sancionaba su nacimiento oficial como fotoperiodista independiente $-\mathrm{O}$, mejor dicho, la aparición de su nombre en el mapa de la profesión-, en un momento histórico en el cual París era un caldo de cultivo para la elaboración en marcha de una nueva concepción de la información periodística, un espacio urbano donde la ebullición política y cívica, que pocos meses después alimentaría en las urnas la formación del Frente Popular francés, llenaba a diario las calles de sujetos ideales para experimentar diferentes técnicas de captura de imágenes relevantes para las masas (eso es, huelgas, pintadas, mítines y banderas). Para cuando la revista Regards publicó el reportaje de Capa sobre la manifestación masiva del 1 de mayo del 1936 -para el cual no es posible establecer si hubo o no alguna aportación de Taro-12, cada miembro de la pareja ya había adoptado el pseudónimo que, según múltiples fuentes testimoniales (entre ellas, las de Schaber), fue invención de la misma Gerda. Se trataba no solamente de nombres artísticos funcionales al marketing de las instantáneas en un mercado extremadamente competitivo y acostumbrado, por lo tanto, a pagar compensaciones inadecuadas, sino también de dos alias fonéticamente incisivos -fáciles de recordar y vagamente reminiscentes de los nombres de Frank Capra y Greta Garbo-y, sobre todo, opacos desde los puntos de vista de la procedencia geográfica y cultural, ya que no podían reconducirse directamente a ninguna lengua, país o religión ${ }^{13}$.

10 A las características técnicas de la fotografía, que hacían de ella un signo extremadamente eficaz para la reproducción capilar y la circulación de la propaganda y del mensaje político, cabe añadir el hecho de que tanto por su ambiente de procedencia, donde por lo general ya se habían acercado al movimiento de los trabajadores, como por sus condiciones de vida en París, numerosos fotógrafos internacionales que movían sus primeros pasos justamente en la capital francesa de la época mostraban una adhesión convencida, sólida y en absoluto artificiosa a la acción del ambiente obrero (para un recuento que recoge, entre otras, las perspectivas de Fred Stein, Robert Capa y David Seymour y frecuentaciones de Taro en París, véase Goebel y Weigel, 2012).

${ }^{11}$ El carnet de acreditación de Taro, del que pueden inferirse los datos citados arriba a pesar de que se haya perdido un cuarto de la hoja en que va mecanografiado, está reproducido, entre otras publicaciones, en Schaber (2007: inserto fotográfico).

12 Además del catálogo digital de la agencia Magnum y del International Center of Photography, de libre acceso, contienen un compendio del servicio de Capa sobre el 1 de mayo Aronson-Budhos (2017) y Lebrun-Lefebvre (2011).

13 Según la reconstrucción de Richard Whelan (1994: 81-82), “derived from Frank Capra's [and that of] the actor Robert Taylor", "Robert Capa was a perfect name for a stateless person. At the same time, Gerda took an almost equally cosmopolitan pseudonym for herself. Henceforth she would be [...] Gerda Taro [...], a name easy to pronounce, to spell and to remember, and it too was rich in associations. [...] Gerda Taro sounds a bit like Greta Garbo, who in 1936 was at the peak of her fame. [...] Anyone who adopts a pseudonym is telling the world a fiction about himself, but, like most fictions, it reveals much about the teller". 
De aquí hasta el momento en que salió rumbo a España junto a su compañero, la autocreación del personaje dirigida por Taro se fue crecientemente hermanando con su contacto constante y solidario con el movimiento internacionalista de los trabajadores, que, a medida que se hacía cada vez más patente la amenaza expansionista de la ideología que ya se había hecho con el poder político en Italia y Alemania, abogaba por un discurso contra-nacionalista basado en la universalidad de las condiciones del proletariado y en la necesidad urgente de una unión antifascista que encontrara en la afinidad política un motivo de cohesión frente al enemigo común. Receptiva, como ya se ha observado, a los movimientos sindicales dentro del contexto urbano, Taro también forjó su cercanía, cuando no su adhesión a la "idéologie de gauche" (Leenaerts, 2010: 181) desempeñando su trabajo de agente y promotora del misterioso Robert Capa en revistas y periódicos que apoyaban las varias coaliciones y organizaciones izquierdistas, misión que, además, la llevaba a escribir pies de fotos y breves textos de comentario por medio de los cuales empezó a tomar el pulso del naciente lenguaje verbo-icónico que justamente en la guerra de España se estrenaría como pieza clave de la cobertura fotoperiodística ${ }^{14}$.

Considerando que cuando llegó a España en agosto de 1936 todavía no había registrado un sello independiente para su propio trabajo, ni había hecho que su nombre constara detrás de las fotos que seguía vendiendo bajo la firma de Robert Capa -lo cual, según explica Richard Whelan, hace que el trabajo de identificación de sus primeras obras se convierta en "una novela policial" (en Schaber et al., 2009: 41) ${ }^{15}$-, cabe intentar entender cómo en menos de un año Taro se convirtió, a raíz de su muerte, en una suerte de heroína política, acogida en Francia por una multitud conmovida y compuesta tanto por autoridades internacionales como por parisinos comunes.

\section{EL TRABAJO DE TARO EN LA GUERRA DE ESPAÑA}

Más allá del carácter trágico que envolvió las circunstancias de su fallecimiento -Taro fue aplastada por un tanque republicano a lo largo de una retirada de la recién perdida batalla de Brunete -, como es de esperar, el motivo de semejante homenaje subyace ante todo en la conciencia política con la que tanto ella como los demás fotógrafos desempeñaron su trabajo en defensa -no por iconográfica menos eficaz que la militar- de la legitimidad de la República

\footnotetext{
14 En su biografía, Schaber comenta el énfasis de las glosas de Taro como un indicio más de su solidaridad con las multitudes organizadas.

15 Sobre la base de un cotejo de archivo entre negativos y antiguas estampas con firma Capa y documentos análogos, pero de diferente formato, que llevan la indicación "Taro", Whelan clasifica las instantáneas sin firma apoyando su hipótesis sobre el tipo de cámara con la que fueron tomadas: según el biógrafo de Capa, de hecho, en un primer momento él trabajaba con una "Leica 35mm", que luego traspasó a su compañera en Madrid, en febrero de 1937 , mientras que ella utilizaba una "Rolleiflex 6x6" (en Schaber, 2009: 43). Cabe anotar que el mismo Capa no mostró ningún interés por la definición de la paternidad correspondiente al trabajo de los primeros meses en España, ya que al publicar Death in the making -dedicándolo "to Gerda Taro. Who spent one year in the Spanish front. And who stayed on"- no se preocupó de aportar ninguna distinción entre los materiales fotográficos allí reproducidos (Capa, 1938).
} 
española y de la resistencia del pueblo de España alistado en el ejército popular16. Firmemente convencidos de que en la península ibérica se empezaba a gestar un ensayo general de la ya inminente guerra mundial, fotógrafos, escritores, intelectuales y, más tarde, voluntarios internacionales de procedencia social transversal se propusieron desde el principio alertar la opinión pública del resto del continente alrededor de los peligros relacionados con las posibles repercusiones europeas del triunfo en España de un golpe de estado fascista sobre la coalición del Frente Popular ${ }^{17}$. La imagen, entonces, lejos de proponerse como mero medio de transmisión de la crónica desde el frente y la retaguardia, asumía plenamente su papel de filtro parcial, de signo ambiguo (eso es, nunca inocente), cuyas variables en apariencia meramente estéticas -la luz, la angulación, el corte, el plano- se convertían en armas contundentes que articulaban un claro llamamiento a la lucha antifascista. Esta "fotografía de resistencia" (Bertelli, 2017: 96), entonces, si por un lado ensalzaba el carácter apasionado, espontáneo, idealista e intrínsecamente proletario del ejército popular y de sus sostenedores, por el otro intentaba desmontar minuciosamente la propaganda antirrepublicana, que, por mano de los nacionalistas, difundía sobre todo por la Europa controlada por el eje un miedo tremendista a las hordas filosoviéticas que supuestamente controlaban las zonas no sublevadas ${ }^{18}$. La misión contrapropagandística contrastaba semejante narrativa presentando instantáneas que retrataban un sistema político armónico de cooperación y socorro mutuo entre los trabajadores y el Estado, a la vez que documentaba la brutalidad de los ataques franquistas, que no tenían reparo en emplear la más reciente tecnología bélica en contra de la población inerme. Además de la información y concienciación de un público amplio, el objetivo también era recaudar consenso con vistas a ese aidez l'Espagne19 que nunca llegó a concretarse más allá del esfuerzo ejemplar llevado a cabo por las Brigadas Internacionales.

En una Barcelona que fue primera etapa del recorrido español de Taro y que todavía no se había convertido en escenario emblemático de los bombardeos franquistas, la fotógrafa se dedicó a capturar imágenes del ejército popular, cuyo objetivo primario parece ser el énfasis del espíritu transversal y colaborativo de las agrupaciones, tanto organizadas como voluntarias, que prestaban su obra en defensa de la República ${ }^{20}$. Con un interés específico por la expresión alegre y valiente

\footnotetext{
16 Para un análisis de la concentración de periodistas internacionales en España después del verano de 1936, véase Preston (2011).

17 En palabras de Enrique Moradiellos (2012: 184), "la propaganda de la República”, a cuyo mensaje se adhería Taro, como la mayoría de sus compañeros, "desarrolló una línea de actuación dirigida a presentar una imagen constante del conflicto español: el gobierno de un Estado democrático y legítimamente constituido estaba haciendo frente, con el masivo apoyo de su pueblo, a un golpe militar fascista promovido y sostenido por potencias extranjeras".

18 Para un cotejo contrastivo entre el material gráfico utilizado por la propaganda de cada bando, véanse LefebvrePeña (2010) y Andrés Sanz (2015).

19 Resulta particularmente significativo con respecto a estas observaciones el pequeño manifiesto que Joan Miró imprimió en la versión formato cartel del famoso proyecto para un sello que nunca vio la luz: "En la lucha actual, veo del lado fascista las fuerzas caducas, del otro bando el pueblo, cuyas inmensas fuentes creadoras darán a España un impulso que asombrará al mundo” (en Cabañas Bravo, 2003: 643).

20 Según apunta Schaber (2007: 122), Taro y Capa aterrizaron cerca de Barcelona el 5 de agosto del 1936, "bien conscientes del hecho de que [en España] se iba a escribir la historia: el revolucionario profesional y la redactora idealista, el obrero anarquista y la miliciana - todos y todas parecían conocer la portada trascendental de los acontecimientos. La sensación de que se estaba viviendo y haciendo un momento histórico trascendente no pertenecía solamente a los protagonistas, sino que también caracterizaba el trabajo de los espectadores profesionales, eso es, los periodistas, fotógrafos y comentaristas".
} 
de rostros en mayoría jóvenes, Taro retrató un aire de fiesta colectiva en la capital catalana alborotada que había preservado su perímetro del levantamiento y se había convertido, como Madrid, en baluarte de la oposición.

En particular, Taro dedicó numerosas tomas a las mujeres combatientes, ejemplo emblemático de los esfuerzos republicanos por la institucionalización de la paridad entre los géneros y elemento propagandístico al que el movimiento proletario internacional se mostraba particularmente sensible ${ }^{21}$. Encuadradas a menudo desde una perspectiva rebajada, con el objetivo sujetado en contrapicado a una distancia corta del suelo, las milicianas resultan imponentes y confiadas en su mono azul que llevan orgullosas como si fuera un traje elegante, las armas en la cintura magnificadas como punctum de la imagen y los rostros marcados bien por sonrisas animadas, o bien por muecas de concentración ${ }^{22}$. En sus negativos, Taro imprime a la mujer no como apéndice del elemento masculino en el ejército, sino como figura autónoma con su propio espacio e identidad dentro de la fuerza militar republicana: en general retratada individualmente o en grupos exclusivamente femeninos, cuando aparece junto a sus compañeros la proporción entre las figuras es equilibrada y las miradas cómplices, nunca jerárquicas ${ }^{23}$. La elección de la fotógrafa se infiere especialmente de la imagen icónica de una joven combatiente entrenando en la playa de Barcelona, cuyo eje central resulta amoldado a la curva sinuosa dada por la silueta de la joven y cuya parte derecha evidencia una triangulación perfecta entre la mirada firme, que apunta hacia adelante, la pistola empuñada justo antes del disparo y el zapato con tacón que parece formar parte del uniforme y hace de contrapunto ponderal a la rodilla hincada de la miliciana 24 .

En Barcelona, Taro también se interesó por una desemantización de las barricadas, que tras haber servido eficazmente para la defensa de la ciudad son, según su elaboración, un paradero bonificado para los niños barceloneses que juegan a la guerra entre los sacos, vestidos de soldaditos y llevando gorros donde van pintadas las siglas de las agrupaciones políticas en las que

\footnotetext{
21 Para una profundización sobre la cuestión femenina en el seno de la República española, véase Nash (1981).

22 Al hablar de punctum como "pinchazo, agujerito, pequeña mancha, pequeño corte, y también casualidad[,] que sale de la escena como una flecha y viene a buscarme[,] me despunta (pero [...] también me lastima, me punza)", hago naturalmente referencia a Barthes (1989).

23 El interés de Taro por la paridad entre hombres y mujeres en la acción común se aprecia, por ejemplo, en el retrato de dos milicianos sentados al lado uno de la otra, ambos envueltos en el uniforme y enmarcados en la parte derecha por la caña de un fusil que no es divisivo, sino que se configura como arma común, al igual que lo es la carcajada que los dos jóvenes comparten en la parte central de la imagen (reproducción en Schaber et al., 2009: 57). Símilmente, en otra toma que retrata a cuatro miembros de las milicias populares, Taro captura el intercambio colaborativo de miradas -y, una vez más, animado- entre dos hombres que, pese a resultar colocados sus rostros en el centro perfecto del cuadrado, comparten el punctum con la inscripción en catalán Front Popular (que se lee en la puerta del coche en que van subidos), y dos mujeres que ocupan por entero los márgenes de la instantánea (foto en Schaber, 2009: 56). A propósito de la cuestión señalo, sin compartir del todo su punto de vista, que Everly (2016: 149) mantiene que "Taro saw the war as a gendered construct".

${ }^{24}$ La imagen, publicada con glosa "En patrouille" en el editorial "Quand les femmes s'en mêlent" de la revista $V u$ (23 de agosto de 1936), aparece como portada del catálogo recopilado en Schaber et al. (2009, también en la página 55) a raíz de la exposición itinerante Gerda Taro, organizada en el año 2007 por el International Center of Photography de Nueva York. El catálogo, complementado con las reproducciones de las imágenes de Taro disponible en el archivo digital del International Center of Photography, se ha utilizado como fuente iconográfica preferente para las observaciones aquí formuladas.
} 
probablemente militan sus padres (C.N.T. y F.A.I. en las reproducciones que aparecen en Schaber et al., 2009: 58-59)25. Símilmente, la fotógrafa retrató por la ciudad la asombrosa pluralidad de banderas, efigies y nombres de partidos pintados en las paredes o grabados en vehículos, cristales y superficies variadas, acaso con la intención de fortalecer, con vistas a la opinión pública internacional, una interpretación del Frente Popular como multiplicidad compacta e inclusiva, hacia la cual todas las fuerzas democráticas de Europa estaban llamadas a brindar su ayuda.

En los meses sucesivos Taro fue acercándose a diferentes frentes de guerra y al parecer aceleró la búsqueda de un estilo fotográfico propio que le permitiera emanciparse del lenguaje iconográfico y de la fama ya arrolladora de Capa. Según reconstruye Schaber (2007), la firma "photo Taro" empezó a acompañar la de su compañero en diferentes reportajes del frente aragonés, donde la fotógrafa repartió su trabajo entre las maniobras militares en la Sierra, con los combatientes republicanos a menudo fotografiados sin uniforme específico y empuñando o cargando armas evidentemente datadas, y la retaguardia campesina en plena actividad. Pese a que el enfoque de Taro en los labradores no despertara un interés particular en las agencias de prensa de la época ${ }^{26}$, juntando las imágenes cabe anotar una correspondencia de movimientos, posturas y, una vez más, miradas indómitas entre los sujetos tanto militares como del campo, tal vez con la intención de volver a subrayar la cohesión de la clase trabajadora española, su esfuerzo común, aunque heterogéneo, por la alimentación del primer sistema político que les resultaba favorable y, al mismo tiempo, sus condiciones de vida y de lucha, no disímiles de la de sus homólogos en el resto de Europa.

Siguiendo la sucesión de sus fotos, para los primeros meses de 1937 Taro había obrado en el frente meridional y en la capital. En Málaga y Almería su interés también había gravitado alrededor del retrato, por medio del cual, gracias a la condensación extrema que permite la instantánea, trató de capturar en pocas expresiones faciales el desaliento de los prófugos que abandonaban la ciudad costera recién caída en manos de los sublevados. Prefiriendo a las tomas en movimiento grabadas por Capa en la carretera una perspectiva más estática, que espía a sus sujetos durante momentos de reposo y reflexión forzada, Taro consigue imprimir en sus negativos la sensación del hogar desgarrado, capturando camas improvisadas, niños desorientados, bebés harapientos, ancianos agotados, heridos y mujeres con la mirada perdida en una congoja que las enajena ${ }^{27}$. De su primera cobertura de la resistencia en Madrid sobresale el mismo énfasis por el impacto humanitario de la guerra en la población española, en este caso difundido a través de retratos múltiples de las cicatrices estructurales causadas por los primeros

\footnotetext{
25 Por medio de más imágenes de vida diaria y diversión familiar, a menudo articuladas como retratos de adultos en uniforme con niños al lado, Taro parece querer articular una retórica visual de la impenetrabilidad ante el ataque, subrayando la eficacia de la resistencia llevada a cabo por el pueblo y el gobierno amenazados por la sublevación nacionalista.

${ }^{26}$ Schaber (2007: 127) observa que "las instantáneas que Gerda sacó de la cosecha en Aragón acaso se deban aunque la reforma agraria constituía un tema de actualidad- sobre todo a la falta de sujetos relevantes en la línea del frente". Puede que semejante descalificación del conjunto de fotos vaya conectada con su escasa exaltación política, ya que en estas no aparecen gestos icónicos ni iconografías sindicales.

${ }^{27}$ La referencia es aquí a la imagen en la que Taro retrata a una mujer con el rostro dirigido hacia un punto imprecisado de la habitación, una mano abrazando su propia cintura y la otra a un lado de la cara como sujetándola, y alrededor varios niños pegados a sus faldas y un anciano descansando en un camastro (reproducción en Schaber et al., 2009: 90). Para una crónica dramatizada del éxodo en la carretera Málaga-Almería, véase León (2007: 193-198).
} 
bombardeos nacionalistas en la zona de la Ciudad Universitaria. Los retratos infantiles de los huérfanos alojados en los comedores sociales, donde el alimento y las actividades comunitarias constituyen los ejes visuales y emotivos de las tomas de Taro, parecen tener el objetivo añadido de informar alrededor de las iniciativas promovidas por la República en ayuda a la población ${ }^{28}$, a la vez que insisten en la oposición maniquea entre el sistema amenazado, en cuyas prioridades sobresale la protección de sus ciudadanos, y la coalición rebelde, responsable de su condición miserable. Una vez más, la finalidad última era la activación transversal, tanto en las altas esferas de la política internacional como en la opinión pública, de una analogía que convirtiera el conflicto español en una prioridad de los movimientos democráticos de Europa.

Donde la cámara de Taro alcanzó, quizás, su autonomía definitiva y, a la vez, contribuyó de manera más impactante al intento de constitución de una conciencia europea de clase y de ideología política frente al nacionalismo, no por transversal menos incisiva, fue entre marzo y julio de 1937 en distintos escenarios de la ciudad de Valencia, objetivo de bombardeos a partir de las primeras semanas del año ${ }^{29}$. Oponiendo pruebas a la campaña fascista que anunciaba una derrota republicana inminente por inferioridad militar y tecnológica, Taro retrató tanto el entrenamiento de grupos ya organizados del ejército republicano como la selección de nuevos soldados y su reclutamiento en los espacios urbanos destinados, en tiempos de paz, a la diversión de la comunidad, como las plazas y las arenas. A la denigración por parte de los nacionales, que se jactaban de combatir en contra de un ejército de aficionados ideológicamente resquebrajado y militarmente inferior, Taro respondía con planos amplios y panorámicas que enseñan una multitud organizada y dispuesta a la lucha; su objetivo se detiene en los rostros tensos de las primeras líneas, a la vez que busca las regularidades geométricas de las columnas y las marchas militares, que transmiten una impresión de orden y disciplina donde el enemigo quiere ver caos e insubordinación.

En mayo capturó los efectos devastadores de un raid aéreo produciendo su serie quizás más impactante, que consta de una sucesión de retratos tomados en la morgue de la ciudad, con violentos planos medios en picado, que se enfocan en los ojos apagados de los muertos tendidos sobre el mármol, o graban detalles extremadamente enfáticos, como lo hace la fotografía de un niño y de un adulto colocados uno al lado del otro, tomada desde la angulación de sus pies como si se tratara de dos crucifijos laicos ${ }^{30}$. En este caso, la fotógrafa optó por el mecanismo opuesto

\footnotetext{
28 Se trata, una vez más, de una operación de contrapropaganda, que pretende desmentir la versión nacionalista que describía el gobierno republicano como un tirano despiadado que condenaba su población al hambre, al desamparo y a una carnicería injustificada. Contribuyen a la misma finalidad, en este caso en contra del estereotipo iconoclasta, las fotografías tomadas durante la edificación de las barricadas para proteger los monumentos de la Plaza de Cibeles (reproducción en Schaber et al., 2009: 103)

${ }^{29}$ Schaber (2007: 147) evidencia que "desde los comienzos de su trabajo común en España, Gerda había sobre todo publicado bajo el copyright común, ese Capa imaginario, y solo ocasionalmente como Photo Taro. [...] Sin embargo, a partir de 1937, reconstruyendo su recorrido sobre la base de las imágenes publicadas, se entiende que para Gerda Taro se hizo cada vez más necesario distinguir claramente sus fotos de las de la producción común firmada Capa\&Taro".

${ }^{30}$ El reportaje consta de una serie gemela dedicada a los heridos en el hospital de Valencia e igualmente diseminada de rostros, en este caso vendados, ensangrentados y doloridos. Se trata de una página de la obra de Taro en la que el blanco, el negro y los grises, otorgando la fotógrafa una gran relevancia a las manchas lúcidas y viscosas, deja intuir con gran eficacia el cromatismo carmesí de la sangre.
} 
con respecto a la impresión de masa que había querido despertar con el reportaje precedente, ya que se decantó por una marcada individualización de los efectos de la guerra, esto es, por la solicitación de un mecanismo de empatía del receptor hacia el sujeto, que imponía al observador, desacostumbrado a la exhibición fotográfica de la muerte, la identificación y, en consecuencia, una reflexión íntima sobre los efectos de una posible guerra en su mismo territorio ${ }^{31}$.

Al ser testigo como reportera del Segundo Congreso Internacional de los Escritores en Defensa de la Cultura, celebrado en julio de 1937, Taro se preocupó ante todo de reproducir una sensación de unidad y participación hacia la causa republicana de los intelectuales involucrados: por una parte inmortalizó la entonación de himnos políticos con el puño en alto, para esas alturas ya símbolo universal de la lucha proletaria, por la otra realizó retratos dinámicos de los participantes en plena actividad. Al mismo tiempo, como otros fotógrafos enviados a Valencia para cubrir el evento, acompañó las delegaciones que visitaron el frente de Guadalajara para imprimir en sus negativos la preocupación de los invitados internacionales, tachados de peones del gobierno soviético por los medios de comunicación alineados con la rebelión, por el pueblo.

Mientras tanto, el punto de mira de sus fotografías de guerra se acerca cada vez más a la línea del frente: en localidades distintas de la geografía española -Navacerrada, Segovia, Carabanchel, Córdoba y, finalmente, Brunete- el objetivo de Taro parece posicionado literalmente al pie del cañón, por lo cual la acción se hace más movediza y concitada, los retratos frontales tienden a desaparecer en favor de sujetos grabados en movimiento, normalmente de espaldas -y por lo tanto no perfectamente enfocados-, y abundan la artillería y las escenas de socorro a los heridos militares. El pueblo del Madrid del ¡No pasarán! seguía resistiendo -lo confirma la breve serie en la que Taro retrató a los obreros de una fábrica de municiones en plena actividad-, pero el acoso a la República iba recrudeciéndose: cerca de Brunete los eslóganes y los símbolos de Falange empiezan a hacer incursión tanto en el paisaje, pintados en las paredes de los edificios, como en las efigies de los prisioneros del bando contrario fotografiados por Taro; a la vez, las expresiones de los soldados dejan transparentar los primeros atisbos de desaliento y la devastación de las zonas recién ocupadas por los nacionales adquiere un tono netamente catastrófico, con llamas y paredes derrumbadas.

\section{LOS AVATARES DEL MITO POLÍTICO DESDE 1937 HASTA NUESTROS DÍAS}

Tanto los testigos de los últimos días de Gerda Taro como la leyenda que se fraguaría inmediatamente después de su muerte subrayaron la insistencia de la fotógrafa por tratar de inmortalizar una victoria republicana, con tal de levantar los ánimos de la población lealista -y de las Brigadas Internacionales, todavía activas en numerosas zonas de guerra- y enseñar a las potencias del eje neutralista anglo-francés -que seguían sin brindar su ayuda, cuando no oponiéndose de facto a la supervivencia del gobierno-, que la República no estaba retrocediendo

\footnotetext{
31 Cabe anotar brevemente que el enfoque en el individuo sigue constituyendo en la fotografía de guerra actual (o, más ampliamente, de calamidad) un medio poderoso de sacudida del espectador de su acostumbrada apatía "ante el dolor de los demás" (Sontag, 2011).
} 
en su intento de convertirse en la primera tumba del fascismo de Europa ${ }^{32}$. Sea cual fuere la razón de su presencia tan cerca de la línea del frente en la retirada republicana del 25 de julio de 1937, la noticia de su muerte repentina llenó las páginas de numerosos periódicos españoles e internacionales en los que Taro fue frecuentemente recordada como la primera fotoperiodista fallecida en la acción ${ }^{33}$. Un año más tarde escribió sobre su muerte José Bergamín, a modo de homenaje:

Por las salas inmensas del Monasterio del Escorial -hospital de sangre- hay sublimes silencios entrecortados por gritos sollozantes, por gemidos que expresan la réplica callada y dolorosa, justiciera, de nuestras víctimas sagradas. Entre ellas dejó su último aliento, una niña casi, símbolo de la juventud más pura con su leve figurita graciosa, Gerda Taro... En los silencios del Monasterio quedó grabado para siempre su nombre humilde, invisiblemente escrito con su sangre y la nuestra; la de nuestro pueblo español. (1938: 72)

Su ensalzamiento como heroína del movimiento proletario arrancó la misma noche de su fallecimiento, que tuvo lugar al día siguiente del accidente: María Teresa León, que viajó a El Escorial junto a Rafael Alberti para recoger el cuerpo, recuerda que el ataúd fue depositado "en el jardín de invierno de la Alianza de Intelectuales" de Madrid, donde "velamos a la pequeña heroína francesa como a un soldado" (en Torres Nebrera, 1996: 35). Los tributos tanto de la maquinaria gubernamental como de los intelectuales internacionales y del pueblo, antes español y luego francés, se acumularon en las varias etapas por las que se desenvolvió el regreso a Francia del féretro, organizado, según reconstruye Schaber (2007), por el periódico Ce Soir -no tiene cabida hablar de repatriación para una alemana de orígenes polacos exiliada en Francia y fallecida en España-. Mientras los restos de Gerda alcanzaban la capital tras su paso por València, la localidad transpirenaica de Port Bou y la Gare d'Austerlitz:

Ce Soir y el PCF dieron comienzo a un proceso que sobrepasó notablemente el luto privado. [...] No importaba que Taro no fuera un miembro oficial del partido: su colaboración con un periódico comunista y su cercanía al movimiento del Frente Popular eran suficientes para involucrarla. La historia de su vida, pero sobre todo su muerte en la guerra civil española, habían escrito de antemano su destino como mártir [revolucionaria]. (Schaber, 2007: 195)

Según subraya Schaber, aun sin depauperar las ceremonias de su indiscutida faceta emotiva, el entierro de Taro en el mismo rincón del Père-Lachaise donde se erguía el paredón de fusilamiento, en 1871, de los miembros de la Commune, junto al largo desfile por las calles de París -organizado por el PCF para resultar claramente reminiscente del corteo del 1 de mayo en el que

\footnotetext{
32 En relación con las intenciones y esperanzas de Taro, Schaber (2007) recoge varios testimonios en el marco del fotoperiodismo internacional activo entre Madrid y Brunete, en mayoría convergentes en reconstruir la determinación de la joven por la búsqueda de una imagen triunfal para la República. Entre ellos, merecen especial atención las memorias noveladas de Ted Allan (2015), quien viajaba en el mismo vehículo donde se encontraba Taro en el momento de la colisión mortal e insiste en representar a Gerda como una valiente paladina de los ideales republicanos. También cabe anotar que la intención de Taro parece confirmada por la rapidez con la que, para la edición del 22 de julio, sus instantáneas del "triunfo republicano en la primera fase de la batalla" llegaron a la redacción de la revista Regards (en Solà Solé, 2014: 116).

33 “The Spanish war kills its first woman photographer", según apareció en el reportaje dedicado al accidente de Taro por la revista Life (citado en Arroyo Jiménez y Doménech Fabregat, 2015: 121).
} 
la misma fotógrafa había participado pocos meses antes-, resulta evidente que la organización del evento correspondía a un claro mensaje político:

el partido podía registrar como éxito la participación de los parisinos y el número asombroso de personas en la procesión. Eso no solamente reforzó la cohesión interna del partido, sino que también coincidió con una muestra de la capacidad de movilización de los comunistas. (Schaber, 2007: 202)

Convertida Gerda en una ahijada de París, en una Marianne -o, tal vez mejor dicho, una Rosa Luxemburg- del movimiento internacionalista, antifascista y, tras el esfuerzo del PCE, también obrero, la conversión de su memoria colectiva en lieu de memoire quedó confiada por el mismo partido al escultor italiano Alberto Giacometti, cuya obra a los pocos años fue modificada -esto es, depurada de toda referencia política- tras la ocupación alemana de la capital francesa ${ }^{34}$.

Después de la Segunda Guerra Mundial, espacio temporal en que queda redefinida para siempre la idea de trauma colectivo, el recuerdo compartido de Taro parece disolverse en el olvido: su falta de interés, en vida, por un encasillamiento político preferente la excluye de la memoria conservativa de partido o de gremio; el exterminio de su núcleo familiar en el holocausto corta cualquier posibilidad de evocación dentro de la esfera privada; las condiciones de vida de los antiguos amigos y compañeros, en mayoría emigrados a los Estados Unidos y sospechosos, bajo la cortina de acero, de filo-comunismo debido a sus posturas y frecuentaciones juveniles, hacen que su memoria comunicativa resulte acallada ${ }^{35}$; la conversión de su figura en ficción -donde en las primeras dos décadas después de su muerte aparece a menudo como apéndice romántico de un Capa ya de por sí notablemente estereotipado en las narraciones de numerosos escritores- o en ritual -por ejemplo, en alguna que otra celebración organizada a modo de archivo en la República Democrática Alemana ${ }^{36}$ - no hace sino restar espesor al perfil de una joven que fue, ante todo e indiscutidamente, internacionalista y antifascista. Bajo la capa espesa de las varias narraciones solapadas, poco o casi nada queda transmitido cerca de la contribución de Taro en la configuración del fotoperiodismo moderno, en la consolidación internacionalista de la causa proletaria en Europa y en la concienciación transnacional sobre la situación de vida y lucha de la clase trabajadora española.

Ahora bien, considerado el revival repentino en el interés por el trabajo de Taro que se desencadenó a raíz del redescubrimiento, por el año 2007, de la largamente desaparecida maleta mexicana, que contenía negativos de Capa, Taro y David Seymour, apodado Chim, cuidadosamente catalogados y confiados por el fotógrafo húngaro al compañero Fred Stein antes de su fuga de Europa, cabe preguntarse si en la última década el recorrido vital, profesional e

\footnotetext{
34 En la lápida diseñada por Giacometti podían leerse las palabras “Gerda Taro / 1911-1937 / Reporter Photographe / de Ce Soir / tuée le 25 juillet 1937 / sur le front de Brunete / Espagne dans l'exercice / de sa profesión” (en Read y Kelly, 2009, con un error en la indicación del año de nacimiento, que era en realidad el 1910).

35 Schaber (2007: 215) anota que durante sus investigaciones dio con un expediente del FBI con nombre "Gerta Pohorylle" confeccionado a partir de los nombres contenidos en el diario personal de un excombatiente.

$36 \mathrm{Al}$ mencionar el archivo como emblema de homologación y neutralización de un fragmento de la memoria colectiva que, como resultado del proceso, resulta completamente vaciado de significado actual, me adhiero a la propuesta formulada en Derrida (1995).
} 
ideológico de la fotógrafa se ha de alguna manera recuperado, modificado o actualizado, y en el caso de una respuesta afirmativa de qué forma y con qué resultados ${ }^{37}$.

Dejando de lado las repercusiones desencadenadas por el hallazgo del material en los microcosmos especializados de la fotografía y de la historiografía, despiertan un interés peculiar algunos productos narrativos que, como se ha dicho, podrían colocarse en el marco de la literatura del trauma y de la posmemoria, y que resultan concebidos para un mercado editorial amplio y, en ocasiones, generalista. Restringiendo ulteriormente el análisis a las escrituras ultracontemporáneas protagonizadas por Taro - y descartando, entonces, los numerosos productos de ficción en los que su personaje se limita a hacer aparición, como por ejemplo en Poniatowska (2016) - pueden aislarse tres novelas publicadas en países distintos: a saber, L'ombre d'une photographe, Gerda Taro, de Françoise Maspero (2006); Esperando a Robert Capa, de Susana Fortes (2009) y La ragazza con la Leica, de Helena Janeczek (2017). Los tres textos, profundamente distintos tanto en su planteamiento como en su retrato de Taro, tienen en común un evidente interés trans-semiótico por la recuperación de la obra de la protagonista a través de descripciones detalladas de sus instantáneas diseminadas por las tramas ${ }^{38}$. Como frecuentemente acontece en la literatura de la memoria, cada novela juega con el patrón docu-ficticio, ya que simula entrevistas con personajes reales o intercala su narración con la presencia textual de documentos simulados, que tratan de inducir en el lector una impresión de realidad, que siempre acaba resultando engañosa ${ }^{39}$. En lo referente a la caracterización de Taro, a partir de los momentos principales de su biografía -las primeras interferencias del nazismo en su vida familiar en Leipzig, el estilo de vida bohémien de los primeros meses en París, el contacto con Robert Capa, la solidaridad con la causa republicana- los tres textos se alejan cada uno a su manera de la mitología política creada alrededor de la fotógrafa, confutando indirectamente la posibilidad de que esta pueda encontrar cabida en el discurso cultural contemporáneo, por lo menos sin la formulación de salvedades sustanciales.

De entre los tres textos, el de Fortes probablemente resulte el que más sentimentaliza -y, entonces, reduce y allana- la figura de Taro, apostando sobre todo por el elemento carnal y sexual de la relación con Capa ${ }^{40}$ y arrancando a menudo su narración de las páginas de un diario ficticio de la fotógrafa, que en la mayoría de los casos presenta un improbable aura dulzona, infantil y enfática. En la guerra civil española, Fortes (2009: 128) ambienta el cumplimiento de la búsqueda

\footnotetext{
${ }^{37}$ Según resume Flores Arancibia (2010: 173), "el hallazgo de la maleta mexicana (en realidad, tres maletines, tres cajas de cartón), fue anunciado en 2007, pero hay antecedentes y entretelones que se remontan a 1995". Las circunstancias a la que alude la cita, que coinciden con más de diez años de tratativas entre Cornell Capa y el propietario del material para su adquisición en el Centro Internacional de Fotografía de Nueva York, resultan detalladamente deshilvanadas en Ziff (2011). Al hablar de redescubrimiento hacia el año 2007 se hace referencia aquí no a la individuación y atribución del contenido de la maleta por parte de los especialistas del sector, sino, más bien, a su sustancial desconocimiento entre el público generalista.

38 En el caso de Maspero y Janeczek, los libros contienen reproducciones de una selección de fotografías.

39 El acercamiento -siempre sin intersección- entre realidad y ficción también se produce por medio de la declaración explícita de las fuentes documentales colocada en las notas finales de los tres textos. Para un comentario profundizado de la docuficción en la narrativa española actual, remito a la recopilación de Tschilschke y Schmelzar (2010).

40 Pese a adherirse el interés de la autora al personaje de Gerda, como sugiere el título el eje gravitacional de la trama es Robert Capa.
} 
de la identidad por parte de su personaje, que "gradualmente" se va "despegando de sus orígenes" y encuentra una dimensión ideal en el internacionalismo de la lucha (Fortes, 2009: 128). El paso de Taro por España parece, además, brindar la ocasión ideal para insertos de talante didácticos sobre el pasado reciente, de los cuales surge un retrato del personaje como heroína romántica, prototipo de la mujer emancipada, del valor en la lucha y de un compromiso con una causa que, sin embargo, presenta colores políticos desteñidos y sin identificar.

Posicionada en una zona de contacto entre la biografía novelada y la novela tout court, la obra de Maspero se abre con una proyección ucrónica -inmediatamente desmentida- en la que el autor se retrata a sí mismo realizando una entrevista imposible con una Gerda Taro anciana, para la cual el conflicto de España, Capa y el accidente del tanque del que se salvó de milagro no son sino recuerdos lejanos. Más interesado en las sombras de la vida y del mito de Taro -concebidas no como manchas en su pasado, sino más bien como fragmentos todavía no colonizados por interpretaciones ajenas- la intención de Maspero parece coincidir ante todo con la devolución a la joven de su papel protagonista en la "batalla de las imágenes", tarea arriesgada, mortal incluso, descrita en este caso más allá de la leyenda como compromiso íntimo con la lucha antifascista ${ }^{41}$. Presentando a Taro como un personaje en contacto constante con impulsos revolucionarios heterogéneos y con las máximas personalidades del panorama político de la época, Maspero se opone al relato político unilateral y fósil de su recuerdo, y aboga por una exaltación del sacrificio de la fotógrafa en la lucha en nombre de una libertad universal a la que ella misma no renunció hasta el momento de su muerte.

El aspecto sobresaliente de la novela de Janeczek, por último, es su carácter mimético con respecto al filtro deformante que es la memoria tanto individual como colectiva. Fragmentaria, plurívoca, opaca, a menudo inaccesible, la información sobre Taro se desprende de su trama de la única manera posible, es decir, a través de los recuerdos de tres testigos inevitablemente parciales que sobrevivieron a la que fue su amiga -Willy Chardack, Ruth Cerf y Georg Kuritzkes, sorprendidos todos en una suerte de monólogo interior-, y gracias al trabajo de investigación y formulación de hipótesis llevado a cabo por la autora misma, cuya presencia declarada en el prólogo y en el epílogo es una suerte de sugerencia del trabajo que queda encomendado al lector. Lector al cual Janeczek parece querer recordar, en tiempos de verdades al parecer absolutas y fácilmente accesibles, que la memoria, y junto a ella ninguna otra reconstrucción, nunca es exhaustiva ni inocente.

\section{CONCLUSIONES}

Si a partir de estas ficciones se quisiera sacar algún tipo de conclusión alrededor de la consistencia actual de Gerda Taro dentro del recuerdo compartido -o, podría decirse, dentro del equipaje mnésico de la cultura europea y, más extendidamente, occidental-, probablemente no podría sino afirmarse que su memorización como obrera de la imagen al servicio de ideales internacionalistas y antifascistas queda todavía pendiente de una recomposición completa, que se proyecte más allá del estereotipo o de la exposición episódica y localizada. De la misma manera, su espacio dentro de la cultura proletaria resulta de momento sin restaurar de forma apropiada,

41 Cita en Maspero (2006: 96). 
desde múltiples puntos de vista (historiográfico, de la cultura popular, del antifascismo europeo, narrativo).

No obstante, la atención transversal y activa que, también gracias a la cada año mayor difusión y circulación de su trabajo, Taro ha despertado en la época reciente tras la acumulación movediza de narraciones alrededor de su persona y su obra sugiere que con el boom de la posmemoria que hace de marco a las ficciones arriba mencionadas se haya puesto en marcha una renegociación dialógica, plural e internacional de su figura, a la que el presente artículo ha pretendido contribuir utilizando su obra $-\mathrm{y}$, por ende, su aportación 'fundacional' a los comienzos del fotoperiodismo internacional- como eje focal. Se trata de un proceso plural que todavía no ha puesto el punto final a su(s) memoria(s), pero que sí defiende la necesidad de una reconstrucción más articulada e inclusiva de su aportación a la lucha antifascista y a la acción en favor de la segunda República española, aligerando la retórica triunfalista del mito político y confutando -aunque todavía de forma incompleta- lo que queda del reduccionismo pseudorromántico que durante décadas ha enmarcado el recuerdo de la pequeña rubia. 
BIBLIOGRAFÍA

AlLAN, Ted (2015). This time a better Earth. Ottawa: University of Ottawa Press.

ANDRÉS SANZ, Jesús de (2015). Carteles de la Guerra Civil Española. Madrid: Susaeta.

Aragon, Louis (1935). Pour un réalisme socialiste. París: Denoél.

Aronson, Marc y Budhos, Marina (2017). Eyes of the world. Robert Capa, Gerda Taro and the invention of modern photojournalism. New York: Henry Holt \& Co.

Arroyo JimÉnez, Lorna Beatriz y Doménech FABregat, Hugo. "Gerda Taro y los orígenes del fotoperiodismo moderno en la guerra civil española”. Fotocinema 10 (2015): 119-153.

BARTHES, Roland (1989). La cámara lúcida. Notas sobre la fotografía. Barcelona: Paidós.

Benjamin, Walter (2003). La obra de arte en la época de su reproductibilidad técnica. México D.F.: Ítaca.

Bergamín, José. “Cristal del tiempo”. Hora de España XIV (1938): 69-75.

BerTelLI, Pino (2017). La fotografia ribelle. Rimini: NdA Press.

Butler, Judith. "Performative Acts and Gender Constitution: an Essay in Phenomenology and Feminist Theory". Theatre Journal 4, 40 (1988): 519-531.

CABAÑas BRAVO, Miguel (coord.) (2003). El arte español fuera de España. Madrid: Consejo Superior de Investigaciones Científicas.

CAPA, Robert (1938). Death in the making. Photographs by Robert Capa and Gerda Taro. New York: Covici Friede.

CAPA, Robert (2001). Slightly out of focus. The legendary photojournalist's illustrated memoire of World War II. New York: Modern Library.

CARTIER-Bresson, Henri et al. (2006). Le front populaire des photographes. París: Éditions Terre Bleue.

Denoyelle, Françoise (1997). La lumière de Paris: Le marché de la photographie, 1919-1939. París: L'Harmattan.

DERRIDA, Jacques. “Archive fever. A Freudian impression”. Diacritics 2, 25 (1995): 9-63.

EverLY, Kathryn (2016). “Remembering/Gendering war: Gerda Taro's Spanish Civil War Photographs". Collins, Jacky et al. (eds.). (Re)collecting the past. Historical memory in Spanish Literature and Culture. Cambridge: Cambridge Scholars Publishing: 148-161.

Flores Arancibia, Daneo (2010). "Campo de aparición: vestigio, indicio e interdicto de la mirada (notas para un exilio de imágenes entre México y España”. Azuela de la Cueva, Alicia y González Martínez, Carmen (eds.). México y España: huellas contemporáneas. Murcia: Servicio de Publicaciones de la Universidad de Murcia: 171-190.

FORTES, Susana (2009). Esperando a Robert Capa. Barcelona: Planeta.

Goebel, Eckart y WeigeL, Sigrid (eds.) (2012). "Escape to life". German Intellectuals in New York: a compendium on exile after 1933. Berlín/Borston: De Gruyter. 
HalbwaCHS, Maurice (1950). La mémoire collective. París: Presses Universitaires de France.

HalbWACHS, Maurice (1994). Les cadres sociaux de la mémoire. París: A. Michel.

InTERnATIONAL CENTER OF PHOTOGRAPHy. Archivo general.

JANECZEK, Helena (2017). La ragazza con la Leica. Milán: Guanda.

Jenkins, Brian y Millington, Chris (2015). France and Fascism. February 1934 and the dynamics of political chrisis. London: Routledge.

Lebrun, Bernard y Lefebvre, Michel (eds.) (2011). Robert Capa: Traces d'une légende. París: Éditions de La Martinière.

LEENAERTS, Danielle (2010). Petite histoire du magazin Vu (1929-1940). Entre photographie d'information et photographie d'art. Bruxelles: Peter Lang.

LeFEBVRE-PeÑA, Michel (eds.) (2013). Guerra gráfica. Fotógrafos, artistas y escritores en guerra. Barcelona: Planeta.

LEÓN, María Teresa (2007). Crónica general de la guerra civil. Sevilla: Renacimiento.

Magnum Photos. Archivo general.

MASPERO, François (2006). L'ombre d'une photographe, Gerda Taro. París: Éditions du Seuil.

MORADIELlOS, Enrique (2012). La guerra de España (1936-1939). Barcelona: RBA Libros.

NASH, Mary (1981). Mujer y movimiento obrero en España. México D.F.: Fontamara.

OlmedA, Fernando (2007). Gerda Taro. El periodismo como testigo de la historia. Barcelona: Random House-Mondadori.

PoniATOWsKA, Helena (2016). Tinísima. Barcelona: Seix Barral.

PRESTON, Paul (2011). Idealistas bajo las balas. Corresponsales extranjeros en la guerra de España. Barcelona: Debolsillo.

RACINE, Nicole. "L'Association des Écrivains et Artistes Révolutionnaires (A.E.A.R.). La revue Commune et la lutte idéologique contre le fascisme (1932-1936)". Le Mouvement Social 54 (1966): 29-47.

RACINE, Nicole. "La querelle du réalisme (1935-1936)". Societé \& Représentations 15 (2003): 113-131.

READ, Peter y KeLly, Julia (eds.) (2009). Giacometti: critical essays. New York: Routledge.

SCHABER, Irme (2007). Gerda Taro. Una fotografa rivoluzionaria nella guerra civile spagnola. Roma: DeriveApprodi.

SCHABER, Irme et al. (2009). Gerda Taro. Roma: Contrasto.

SOLÀ SOLÉ, Pere (2014). Louis Aragon y España. Lleida: Edicions de la Universitat de Lleida.

Sontag, Susan (2011). Ante el dolor de los demás. Barcelona: Debolsillo. 
TORRES NeBrerA, Gregorio (1996). Los espacios de la memoria. La obra literaria de María Teresa León. Madrid: Ediciones de la Torre.

TschilschKe, Christian von y SCHMElZAR, Dagmar (eds.) (2010). Docuficción. Enlaces entre ficción y no ficción en la cultura española actual. Madrid: Iberoamericana/Vervuert.

WHELAN, Richard (1994). Robert Capa. A biograpby. Lincoln: Nebraska University Press.

Wolikow, Serge (1996). Le Front Populaire en France. Bruxelles: Éditions Complexe.

ZIFF, Trisha (2011). La maleta mexicana. México y España: 212 Berlin, Mallerich Films y Paco Poch. 